E. M. Phillips, T. MesganaW, A. PATEl, S. DUtTWYler, B. Q. MERCADo, K. N. Houk, J. A. ELLMAN* (YALE UNIVERSITY, NEW HAVEN AND UNIVERSITY OF CALIFORNIA, LOS ANGELES, USA)

Synthesis of ent-Ketorfanol via a C-H Alkenylation/Torquoselective $6 \pi$ Eletrocyclization Cascade Angew. Chem. Int. Ed. 2015, 54, 12044-12048.

\title{
Synthesis of ent-Ketorfanol
}
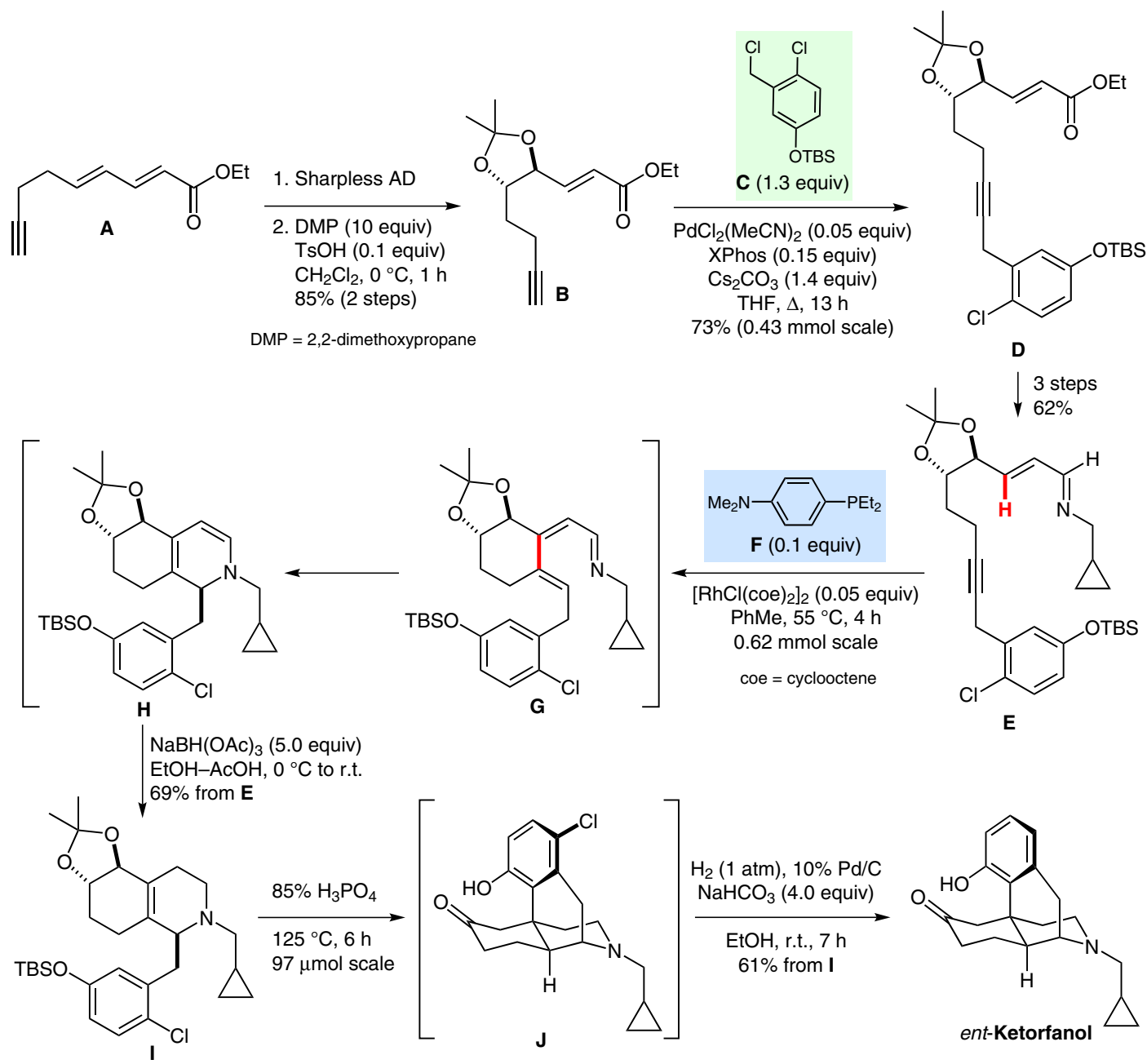

Significance: The synthesis of ent-ketorfanol depicted features a rhodium-catalyzed intramolecular $\mathrm{C}-\mathrm{H}$ alkenylation/ $6 \pi$ electrocyclization cascade $(\mathbf{E} \rightarrow \mathbf{G} \rightarrow \mathbf{H})$ that provides the fused bicyclic 1,2-dihydropyridine $\mathbf{H}$ as a key intermediate. The torquoselectivity of the electrocyclization is a consequence of remote asymmetric induction provided by the isopropylidene-protected diol. Another noteworthy facet is the acid-catalyzed pinacol rearrangement/Friedel-Crafts alkylation $(\mathbf{I} \rightarrow \mathbf{J})$.
Comment: Ketorfanol is a semisynthetic opioid that was previously derived from morphine or naltrexone. It was never marketed. Because both enantiomers of diol $\mathbf{B}$ are readily available by Sharpless asymmetric dihydroxylation, both ketorfanol and ent-ketorfanol can be prepared in eleven steps and $9 \%$ overall yield without recourse to opiate modification. Note the use of the chlorine substituent in I to direct the regioselectivity of the Friedel-Crafts cyclization.

SYNFACTS Contributors: Philip Kocienski

Synfacts 2016, 12(1), 0001 Published online: 16.12.2015

Dol: 10.1055/s-0035-1560992; Reg-No.: K06815SF

\section{Gategory}

Synthesis of Natural

Products and

Potential Drugs

\section{Key words}

ent-ketorfanol

C-H alkenylation

electrocyclization

pinacol

rearrangement

Friedel-Crafts

alkylation

rhodium catalysis

torquoselective cyclization

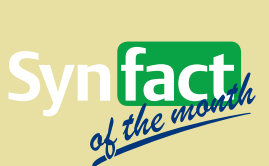

